CURRENT SURVEY

\title{
The value of brain scanning
}

\author{
D. RIDDOCH \\ M.B., M.R.C.P. \\ Z. DROLC \\ B.Sc.
}

\section{Departments of Neurology and Physics, United Birmingham Hospitals}

\section{Summary}

Over a 3-year period, 667 brain scans were performed, of which the results in 632 have been analysed.

Positive scans were found in $68 \%$ of 204 cerebral tumours. There was a high rate of detection of meningiomas and malignant gliomas. Scanning was less helpful in visualizing slowly growing gliomas, and those tumours situated in the mid-line or posterior fossa. Metastases occupied an intermediate position.

Positive scans occurred in a proportion of patients following acute cerebro-vascular accidents, and in a few other miscellaneous disorders.

Virtually all patients with transient cerebral ischaemia, migraine, epilepsy and presenile dementia had normal brain scans.

The value and limitations of this investigation have been discussed.

\section{Introduction}

In recent years radioactive isotopes have been used increasingly in both the diagnosis and treatment of a wide variety of disorders. In neurological and neurosurgical practice, isotope brain scanning has been found to be of value in many centres because of its convenience and reliability. Although expensive in capital outlay and running costs, this must be balanced against the financial saving which frequently results from its use on an out-patient basis, and the consequent saving of costly admission to hospital.

In order to assess the value and limitations of this investigation we have studied the results obtained over the past 3 years in the Physics department of the United Birmingham Hospitals. The technique used stems from the work of Moore (1948), who reported his findings in patients given intravenous diiodo-fluorescein labelled with radioactive iodine. On scanning their heads with a portable GeigerMüller tube, he was able to identify areas of increased radioactivity which corresponded with the sites of

Correspondence: Dr D. Riddoch, Department of Neurology, Queen Elizabeth Hospital, Birmingham, B15 2TH tumours later found at operation. Many different radioactive substances have since been tried, but the one in most common use now is technetium pertechnetate $\left(\mathrm{Tc}^{99 \mathrm{~m}}\right)$. It combines the advantages of suitable single energy gamma-emission and a short half-life, with a total body radiation dose of the order of $100 \mathrm{mrad}$.

\section{Method}

Our practice has been to give $5 \mathrm{mCi}$ of technetium $^{99 \mathrm{~m}}$ intravenously, preceded by Lugol's iodine or perchlorate orally to reduce uptake of radioactive material by the thyroid gland and choroid plexus. Both colour and photoscans were recorded by a Picker Magnascanner, anterior and both lateral views being carried out on all patients, and a posterior view if this was indicated on clinical grounds. Scanning was started 15 min after the isotope had been given, the whole procedure taking about $1 \mathrm{hr}$. Individual scans were considered to be positive if they showed an abnormal area of increased radioactivity. In certain instances, one view revealed a suspicious shadow which could not be identified on the corresponding scan taken at right angles. These scans were deemed equivocal.

\section{Results}

During the 3 years up to the end of June 1970, 667 scans have been performed on 636 patients, the discrepancy in numbers being due to repeat studies on thirty-one cases. In thirty-five patients the clinical information was insufficient to justify an accurate diagnostic label (twenty-four of these being suspected of having cerebral metastases). They were therefore discarded leaving 632 scans for analysis. Of these, $158(25 \%)$ were positive and $441(70 \%)$ negative. The remaining thirty-three $(5 \%)$ scans were considered to be equivocal.

\section{Tumours}

In this series there were 204 patients with cerebral neoplasms (Table 1). The nineteen patients with 
meningiomas all had positive scans. Five of these, including the only example arising in the posterior fossa, had recurred after previous removal. Histologically proven astrocytomas were found in fiftytwo patients and of these thirty-six $(67 \%)$ had positive scans. As can be seen from Table 1, a much higher proportion of abnormal results was found in the malignant (Kernohan grades 3 and 4) tumours than in the more benign and slowly growing (grades 1 and 2 ) neoplasms $(84 \%$ and $52 \%$ respectively). Two of the benign group arose in the cerebellum, both of these being revealed by scanning, and six were recurrent growths.

Of ninety patients with cerebral metastases, scanning was positive in sixty $(67 \%)$. Histological proof of the nature of the tumour, either from operation or post-mortem examination, was available in only twenty-seven patients, but a further sixteen cases had radiological evidence of a cerebral space-occupying lesion in association with known malignancy elsewhere in the body. The diagnosis in the remaining forty-seven was based on clinical grounds. The primary sites were bronchus (forty-two), breast (seventeen), melanoma (four), bowel (three) and miscellaneous (six), with the remainder (eighteen) unknown. $76 \%$ of supratentorial metastases were detected by scanning, compared with $35 \%$ of infratentorial deposits. Multiple shadows were seen in fourteen cases, or $23 \%$ of the positive scans, this appearance immediately suggesting metastases. In three instances the area of increased radioactivity did not correspond with the clinically suspected site of the lesion, and this was regarded as circumstantial evidence in favour of more than one cerebral deposit.

The results obtained in twenty-two patients with miscellaneous histologically proven cerebral tumours are also shown in Table 1 . In addition there were a further twenty-one cases in which no histological proof of tumour type was obtained due to either surgical inaccessibility, or malignancy on clinical and radiological grounds, or refusal of operation by the patient. When all 204 tumour cases are considered, positive scans for neoplasms in the supratentorial compartment were obtained in $74 \%$ as opposed to $41 \%$ for those situated below the tentorium (Table 2). It is interesting that of twentytwo neoplasms which had recurred at varying intervals after surgery, no less than twenty were revealed by scanning.

\section{Vascular lesions}

Table 3 gives the findings in various vascular disorders. The label 'stroke' refers to patients who suffered a single episode of hemisphere dysfunction with prolonged or poor recovery. Two were proved to have intracerebral haematomas and four sustained infarcts as evidenced by internal carotid

TABLE 1. Results of brain scanning in 204 cases of cerebral tumour

\begin{tabular}{|c|c|c|c|c|}
\hline & Total & Positive & Equivocal & Negative \\
\hline Meningioma & 19 & $19(100 \%)$ & - & - \\
\hline Astrocytoma 1 and 2 & 27 & $14(52 \%)$ & 3 & 10 \\
\hline Astrocytoma 3 and 4 & 25 & $21(84 \%)$ & 2 & 2 \\
\hline $\begin{array}{l}\text { Metastases } \\
\text { Histologically proven } \\
\text { Angiographically 'proven' } \\
\text { Unproven }\end{array}$ & $\begin{array}{l}27 \\
16 \\
47\end{array}$ & $\begin{array}{l}21(78 \%) \\
10(62 \%) \\
29(62 \%)\end{array}$ & $\begin{array}{l}1 \\
4 \\
6\end{array}$ & $\begin{array}{r}5 \\
2 \\
12\end{array}$ \\
\hline $\begin{array}{l}\text { Miscellaneous proven } \\
\text { Ependymoma } \\
\text { Oligodendroglioma } \\
\text { Haemangioblastoma } \\
\text { Pituitary adenoma } \\
\text { Sarcoma } \\
\text { Ganglioneuroma } \\
\text { Colloid cyst } \\
\text { Epidermoid } \\
\text { Cylindroma } \\
\text { Vault metastasis } \\
\text { Hodgkin's deposit }\end{array}$ & $\begin{array}{l}4 \\
4 \\
3 \\
3 \\
2 \\
1 \\
1 \\
1 \\
1 \\
1 \\
1\end{array}$ & $\begin{array}{l}3 \\
3 \\
3 \\
-\overrightarrow{2} \\
1 \\
- \\
- \\
1 \\
1 \\
-\end{array}$ & $\begin{array}{l}1 \\
1 \\
- \\
2 \\
- \\
- \\
- \\
- \\
- \\
- \\
-\end{array}$ & $\begin{array}{l}- \\
- \\
- \\
1 \\
- \\
- \\
1 \\
1 \\
- \\
- \\
1\end{array}$ \\
\hline $\begin{array}{l}\text { Miscellaneous unproven } \\
\text { Brainstem 'glioma' } \\
\text { 'Pinealoma' } \\
\text { Hemisphere 'glioma' }\end{array}$ & $\begin{array}{r}5 \\
1 \\
15\end{array}$ & $\overline{-}$ & $\begin{array}{l}2 \\
\overline{2}\end{array}$ & $\begin{array}{l}3 \\
1 \\
2\end{array}$ \\
\hline Total & 204 & $139(68 \%)$ & $24(12 \%)$ & $41(20 \%)$ \\
\hline
\end{tabular}


TABLE 2. Results of brain scanning in 170 supratentorial and thirty-four infratentorial tumours

\begin{tabular}{lcccc}
\hline & Total & Positive & Equivocal & Negative \\
\hline Supratentorial & 170 & 125 & 17 & 28 \\
Infratentorial & 34 & 14 & 7 & 13 \\
Total & 204 & 139 & 24 & 41 \\
\hline
\end{tabular}

TABLE 3. Results of brain scanning in ninety-five cases of cerebral vascular disease

\begin{tabular}{lrcrr}
\hline & Total & Positive & Equivocal & Negative \\
\hline Stroke & 20 & 13 & & 5 \\
0-3 months & 6 & 1 & 2 & 4 \\
3-6 months & 47 & - & 1 & 46 \\
Cerebral arteriosclerosis & 20 & - & - & 20 \\
Transient ischaemic attacks & 1 & - & - & 1 \\
Subarachnoid haemorrhage & 1 & 14 & - & 7 \\
Haemangioma of cerebellum & 95 & & & 77 \\
$\quad$ Total & & & & \\
\hline
\end{tabular}

occlusion on angiography. No attempt has been made to classify the remainder as infarcts or haemorrhages in view of the difficulty this may entail without adequate pathological study. Although the numbers are small, it can be seen that the incidence of positive scans is very much higher in the early weeks following a stroke, than in the later months. No positive studies were found in patients with chronic symptoms from diffuse cerebral arteriosclerosis or those subject to transient ischaemic attacks.

\section{Miscellaneous cerebral disorders}

It can be seen from Table 4 that the vast majority of the remaining scans were negative. Carotid angiography was performed on half the cases of migraine with a normal result in each instance. Most of the patients with epilepsy had either developed fits late in life or the history and electroencephalographic findings suggested a focal origin for their attacks. Amongst these, only one positive scan was found. The patient concerned, whose scan showed an area of increased uptake in the right hemisphere, had left sided focal fits and a normal right carotid angiogram. Unfortunately, she failed follow-up and we are not in a position to know whether or not this was a false positive result. The presence of cerebral atrophy in the group labelled presenile dementia was confirmed by air studies in every case.

The four positive scans in the miscellaneous group were due to single examples of tuberculoma, haemangioma of the orbit, fibrous dysplasia of bone and an arachnoid cyst at the site of a previously removed meningioma. The last of these is probably a false positive from the previous surgery, since two other cases of arachnoid cyst gave negative results. The remaining patients in this group with negative or equivocal scans had a wide spectrum of cerebral disorders including benign intracranial hypertension, Parkinson's disease, encephalopathies and encephalitis, and various degenerative disorders. In addition there were twenty-nine patients in whom the possibility of cerebral metastases or recurrence of a previously excised tumour was not substantiated by the subsequent clinical course. The typical appearance produced by previous craniotomy, namely thickening of the vault shadow on the anterior or posterior view, in association with diffuse patchy uptake in the lateral scan, was seen in fourteen cases. It was most prominent in the first few months following surgery, but in one patient was still visible after 3 years. Diagnostic burr holes produced typical elliptical shadows in nine further instances.

TABLE 4. Brain scan findings in various cerebral disorders

\begin{tabular}{lrccr}
\hline & Total & Positive & Equivocal & Negative \\
\hline Migraine & 26 & - & - & 26 \\
Epilepsy & 109 & 1 & 1 & 107 \\
Presenile dementia & 26 & - & - & 26 \\
Psychiatric disorders & 33 & - & 1 & 32 \\
Miscellaneous & 139 & 5 & 3 & 132 \\
Total & 333 & 5 & 5 & 323 \\
\hline
\end{tabular}


Although false negative results have been quite common, we have only found two false positive scans in this series. Of the thirty-three considered to be equivocal, there were three patients with strokes, twenty-four with tumours, and six with various conditions usually associated with negative scans.

\section{Discussion}

The value of brain scanning in cerebral tumour diagnosis is well established (Brinkman, Wegst \& Kahn, 1962; Bucy \& Ciric, 1965; Bull \& Marryat, 1965; Gold \& Loken, 1969; Goodrich \& Tutor, 1965). It gives a particularly high incidence of positive results in meningiomas and malignant neoplasms, both of which take up isotope avidly (Forster \& Bethell, 1969). Nevertheless, the large proportion of negative and equivocal results $(32 \%$ in this series compared with $10 \%$ for angiography in 115 cases in which this investigation was also carried out) leaves room for concern. By contrast we found only three examples of tumour detection by scanning in the face of completely normal angiography.

The reasons why certain tumours fail to be visualized by scanning are worth considering. It is known that cerebral neoplasms take up isotope in proportion to their blood supply (Cohn \& Soiderer, 1969), so that the detection rate is lower in those which are avascular. Other less well understood factors concern the distribution of the radioactive substance in the individual neoplastic cells and the surrounding interstitial tissue (Jackson, Corson \& Dick, 1967; Tator, Morley \& Olszewski, 1965). Both the size and the site of the lesion, whatever its nature, are also relevant. The resolving power of the scanner is such that it will not detect areas of increased radioactivity which are less than $1 \mathrm{~cm}$ in diameter. Also the scanning probe is so constructed that tumours lying outside its plane of focus are less likely to cast a shadow on the scan. The same is true of lesions which are obscured by such normally radioactively dense structures as bone and muscle. In consequence, tumours lying in the midline, at the base of the brain, or in the posterior fossa, have a comparatively low rate of detection (Du Boulay \& McAlister, 1970; McAfee \& Taxdal, 1961; Overton et al., 1965b). In order to improve the results in infratentorial scanning, Witcofski \& Roper (1965) have recommended that the scanning probe should be tilted to 'open up' the posterior fossa, and the use of vertex views is advocated by Overton et al. (1965a). There is less of a problem in childhood when most cerebral tumours lie in the posterior fossa, because the occipital muscles are smaller (Samuels, 1968). It may be said at this stage that the only limitation of brain scanning in children, is the inability of the younger ones to keep still for the requisite period. This difficulty may be overcome by using a gamma-camera with its much shorter exposure time, although the proportion of tumours detected tends to be slightly lower with this method.

As we have indicated above, a considerable proportion of patients who suffer cerebral hemisphere infarction or haemorrhage will have a positive scan. It has been shown by Glasgow et al (1965) and by Marshall \& Popham (1970) that the highest incidence of abnormal scans occurs $2-4$ weeks after a stroke, and there is a progressive return to normal over the ensuing months. Unfortunately it is also true that the scan appearance of hemisphere vascular damage cannot be distinguished from that of a glioma or metastasis. Consequently before any pathological reliance can be placed on the result it may be necessary to repeat the investigation after the lapse of some weeks to prove that the lesion is resolving. By this time the clinical course has usually resolved any diagnostic doubts. Patients with transient ischaemic attacks have normal scans, and this investigation is only of value in that a negative result gives some reassurance in the differential diagnosis from tumour in doubtful cases. The possibility of extracranial vascular surgery in this condition demands angiography and the same argument applies to arteriovenous malformations, even though the latter are frequently revealed by scanning (Budabin, 1967). Berry aneurysms are seldom of sufficient size to be picked out on the scan, although the brain damage caused by haemorrhage from them may be revealed. In subdural haematoma above all other vascular conditions, scanning is invaluable. The vast majority can be recognized by the characteristic crescent-shaped area of increased radioactivity (Allen et al., 1967; Morrison et al., 1965; Witcofski, Maynard \& Roper, 1967). As many of the affected patients are elderly and arteriosclerotic it has superceded angiography as the investigation of choice in this condition.

Although the majority of positive scans are found in neoplastic or vascular disease, some result from other less common conditions. Apart from those already mentioned, intracerebral abscesses (Gillingham \& Donaldson, 1968) and leukaemic deposits (Davis et al., 1966) have been reported.

It is the contrast in uptake of isotope between focal lesions of whatever sort, and the remaining normal brain which leads to the abnormal shadow on the scan. Generalized cerebral disorders either show no change in this respect, or the alteration in radioactivity is so diffuse that no characteristic picture emerges. The chief advantages of brain scanning lie in absence of morbidity and in accurate localization, in both of which features it is superior to angiography and ventriculography. On the other hand, with a few exceptions, it fails to give any accurate idea of the underlying pathological process. 
Its main application is in the field of tumour diagnosis, and it is unfortunately true that many different types of neoplasms fail to be shown by brain scanning. Consequently, it is when it is used in conjunction with longer established neuroradiological procedures that radioisotope brain scanning is found to be of greatest value.

\section{References}

Allen, M.B., Dick, D.A.L., Hightower, S.J. \& Brown, M. (1967) The value and limitation of brain scanning. Clinical Radiology, 18, 19.

Brinkman, C.A., Wegst, A.V. \& Kahn, E.A. (1962) Brain scanning with mercury ${ }^{203}$ labelled neohydrin. Journal of Neurosurgery, 19, 644.

BuCY, P.C. \& CIRIC, I.S. (1965) Brain scans in diagnosis of brain tumours. Journal of the American Medical Association, $191,437$.

Budabin, M. (1967) Diagnostic value of RIHSA and chlormerodrin ${ }^{197} \mathrm{Hg}$ brain scanning in intracranial arteriovenous malformations. Journal of Nuclear Medicine, 8, 879.

Bull, J.W.D. \& MARRYAT, J. (1965) Isotope encephalography: experience with 100 cases. British Medical Journal, $1,474$.

CoHn, H.J. \& SoIderer, M.H. (1969). Tissue vascularity in positive and negative brain scans. Journal of Nuclear Medicine, 10, 553.

Davis, C.H., Alexander, E., Witcofski, R.L. \& Maynard, C.D. (1966) Brain scanning with ${ }^{99 m}$ Technetium. Journal of Neurosurgery, $24,987$.

Du Boulay, G. \& McAlister, J. (1970) The choice between carotid angiography and brain-scanning in the investigation of tumour suspects. Proceedings of the Royal Society of Medicine, 63, 926.

Forster, D.M.C. \& Bethell, A.N. (1969) The diagnostic value of scintillation brain-scanning. Clinical Radiology, 20, 257.

Gillingham, F.J. \& Donaldson, A.A. (1968) Cerebral radioisotope scanning. Journal of Neurology, Neurosurgery and Psychiatry, 31, 647.

Glasgow, J.L., Currier, R.D., Goodrich, J.K. \& Tutor, F.T. (1965) Brain scans at varied intervals following cerebrovascular accidents. Journal of Nuclear Medicine, 6,902.
GoLD, L.H.A. \& LoKen, M.K. (1969). Retrospective evaluation of isotope images of the brain in 852 patients. Radio$\log y, 92,1473$.

GoODRICH, J.K. \& TutoR, F.T. (1965) The isotope encephalogram in brain tumour diagnosis. Journal of Nuclear Medicine, 6, 541 .

JACKson, G.L., Corson, M.L. \& Dick, J. (1967) The cellular localization of mercury ${ }^{203}$ chlormerodrin in astrocytomas. Journal of Nuclear Medicine, 8, 611.

Marshall, J. \& Popham, M.G. (1970) Radioactive brain scanning in the management of cerebrovascular disease. Journal of Neurology, Neurosurgery and Psychiatry, 33, 201.

MCAFEE, J.G. \& TAXDAL, D.R. (1961) Comparison of radioisotope scanning with cerebral angiography and air studies in brain tumour localization. Radiology, 77, 207.

MOORE, G.E. (1948) Use of radioactive diiodofluorescein in the diagnosis and localization of brain tumours. Science, $107,569$.

Morrison, R.T., Afifi, A.K., van Allen, M.W. \& Evans. T.C. (1965). Scintiencephalography for the detection and localization of non-neoplastic intracranial lesions. Journal of Nuclear Medicine, 6, 7.

Overton, M.C., Haynie, T.P., Otte, W.K. \& Coe, J.E. 1965a) The vertex view in brain scanning. Journal of Nuclear Medicine, 6, 705.

Overton, M.C., Otte, W.K., Beentues, L.B. \& Haynie, T.P (1965b). A comparison of 197 mercury and ${ }^{203}$ mercury chlormerodrin in clinical brain scanning. Journal of Nuclear Medicine, 6, 28.

SAmuels, L.D. (1968) Demonstration of posterior fossa tumours in children. Journal of Nuclear Medicine, 9, 346.

Tator, C.H., Morley, T.P. \& Olszewski, J. (1965) A study of the factors responsible for the accumulation of radioactive iodinated human serum albumin (RIHSA) by intracranial tumours and other lesions. Journal of Neurosurgery, 22, 60.

Witcofski, R.L., MAYNARD, C.D. \& Roper, T.J. (1967) A comparative analysis of the accuracy of the technetium$99 \mathrm{~m}$ pertechnetate brain scan: follow-up of 1000 patients. Journal of Nuclear Medicine, 8, 187.

Witcofski, R.L. \& RoPER, T.J. (1965). A technique for scanning the posterior fossa. Journal of Nuclear Medicine, 6, 754. 